Gut, 1987, 28, 1609-1612

\title{
Reduction of colonic motility by intravenous nicardipine in irritable bowel syndrome
}

\author{
ALISON PRIOR, S R HARRIS, AND P J WHORWELL \\ From the Department of Medicine, University Hospital of South Manchester, Manchester
}

SUMMARY The effect of nicardipine, a new dihydropyridine calcium antagonist, on postprandial colonic motility was assessed in 10 patients with irritable bowel syndrome. Each patient was studied twice receiving intravenously either $\mathrm{N}$ saline or nicardipine after a $100(0)$ calorie meal. In the control study there was a significant $(\mathrm{p}<0 \cdot(01)$ postprandial increase in the contractile activity of the colon, reaching a peak at approximately 20 minutes. Intravenous nicardipine completely abolished the colonic response, with a significant reduction in the number $(p<0 \cdot 005)$ and amplitude $(p<0 \cdot 005)$ of contractions and of the motility index $(\mathrm{p}<0 \cdot() 25)$. These results support the need for further studies to evaluate the therapeutic role of nicardipine in the irritable bowel syndrome.

Disordered colonic motility, both in the resting state and in response to various stimuli, has been reported in patients with the irritable bowel syndrome (IBS)..$^{-1}$ Although the relationship between this abnormal motility and the symptoms of IBS has yet to be shown conclusively an increase in motor activity after a meal is known to be associated with the onset of typical symptoms in some patients, ${ }^{56}$ and suppression of colonic activity by anticholinergics or musculotropics remains one of the mainstays of treatment in this condition. 'The response of many patients to the currently available preparations, however, remains disappointing.

The influx of calcium ions across the cell membrane is known to be of major importance in the contraction of gastrointestinal smooth muscle, ${ }^{,}$and calcium channel blockers might therefore be expected to reduce colonic motor activity. Nicardipine is a new dihydropyridine calcium antagonist known to cause arterial vasodilation in both the cerebral and peripheral circulations via its action on vascular smooth muscle. It was the purpose of the present study to investigate the effect of nicardipine on food stimulated colonic motility in patients with IBS.

\section{Methods}

PATIENTS

Ten patients with IBS (one man, nine women, age

Address for correspondence: Dr P J Whorwell. University Hospital of South Manchester. Nell I.ane. West Didsbury. Manchester M20 8LR.

Received for publication 30 April 1987.
22-64 years) were studied. Irritable bowel syndrome was defined by the presence of abdominal pain and distension together with a disordered bowel habit (constipation - four patients, frequent defecation three patients, alternating - three patients). Postprandial discomfort was graded as mild (two subjects), moderate (four subjects), or severe (four subjects). Symptoms had been present for between four to 15 years and in the month before the study at a frequency of at least three episodes per week. All subjects had normal haematology, biochemistry, and contrast radiology or colonoscopy.

Each subject was studied on two occasions, separated by at least seven days, and received in random order either intravenous $\mathrm{N}$ saline $(20 \mathrm{ml})$ or nicardipine ( $10 \mathrm{mg}$ in $20 \mathrm{ml} \mathrm{N}$ saline). Before the study days all medication was discontinued for at least 48 hours and subjects fasted overnight. Without bowel preparation a triple lumen polyethylene catheter was inserted using a colonoscope and the openings positioned at 25,20 , and $15 \mathrm{~cm}$ above the anal verge. The catheter was perfused with distilled water at a rate of $20 \mathrm{ml} /$ hour using an Arndorfer capillary infusion system and changes in intraluminal pressure recorded on a Lectromed multichannel pen recorder. After a 30 minute adaptation period fasting motor activity was recorded for 40 minutes. A standard 1000 calorie liquid meal consisting of $200 \mathrm{~g}$ double cream flavoured with one sachet of Build Up (fat content $96 \mathrm{~g}$, protein content $12 \mathrm{~g}$, carbohydrate content $29 \mathrm{~g}$, total volume $275 \mathrm{ml}$ ) was then given and motor activity recorded for 40 minutes after its completion. 
As the meal was ingested either $20 \mathrm{ml} \mathrm{N}$ saline or $10 \mathrm{mg}$ nicardipine was administered intravenously as four pulses of $5 \mathrm{ml}$ over a 10 minute period.

Recordings were coded and read blindly. Waves of $5 \mathrm{~mm} \mathrm{Hg}$ or less were excluded from analysis as were sudden pressure changes occurring simultaneously in all three channels secondary to increases in intraabdominal pressure. For each of the three recording levels the number of contractions, mean amplitude of contraction and motility index (the sum of amplitude/ $2 \times$ length of contraction) were calculated. The results at each level were then summated to obtain an overall value. After the meal the recordings were analysed in five minute intervals to allow an accurate assessment of the change in activity. To obtain a single baseline measurement for comparison, activity was summated over the whole 40 minute fasting period and then this total figure divided by 8 to give activity per five minutes. The paired $t$ test was used for analysis.

\section{Results}

In the control study ( $\mathrm{N}$ saline) there was a significant increase in the number of colonic contractions $(p<0 \cdot(01)$, and motility index $(p<0 \cdot 05)$ after the 1000 calorie meal (Figs 1,2). Contractile activity had returned to basal levels by 40 minutes. When the subjects received intravenous nicardipine, however, the postprandial response was abolished in terms of both the number of contractions $(p<0.005)$ (Fig. 1), and motility index $(p<0 \cdot 025)$ (Fig. 2). In addition a significant decrease $(p<0 \cdot 005)$, in the mean amplitude of contractions was noted (Fig. 3).

Intravenous nicardipine was associated with a significant increase in mean pulse rate $(68 v 98 / \mathrm{min})$ and a minor fall in diastolic blood pressure $(74 v$ $70 \mathrm{mmHg}$ ). The drug was well tolerated by all

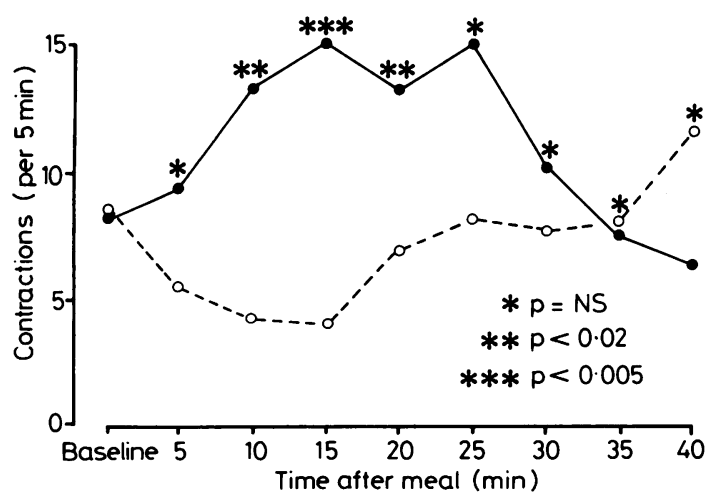

Fig. 1 Effect of nicardipine and saline on colonic contractile activity after meal. $-N$ saline; $\bigcirc---\bigcirc$ nicardipine.

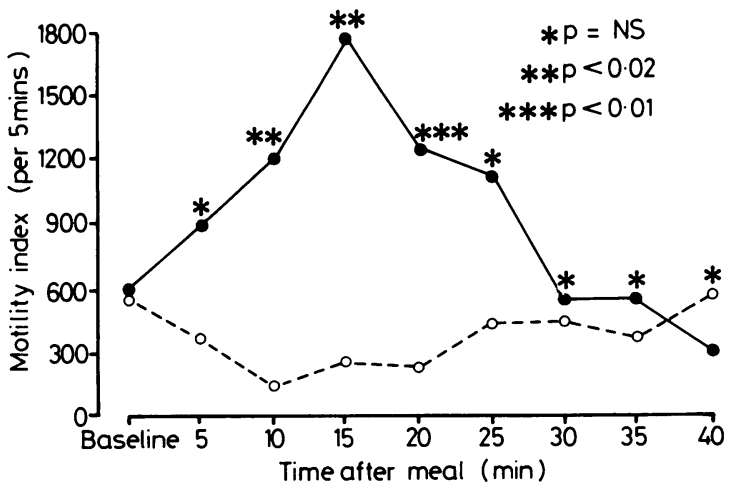

Fig. 2 Effect of nicardipine and saline on the motility index after meal. $-\mathrm{N}$ saline; $\mathrm{O}^{-}--\mathrm{O}$ nicardipine.

subjects although two patients noted transient flushing of the legs after injection. The increase in pulse rate and decrease in blood pressure were asymptomatic. No side effects were noted after infusion of saline.

\section{Discussion}

This study shows that intravenous nicardipine significantly decreases colonic motility in IBS patients in the first 40 minutes after a meal. A number of studies have shown that the colonic response to food consists of an increase in both myoelectrical and contractile activity. ${ }^{11}$ In normal subjects it was originally believed that this response was limited to the first postprandial hour" with a peak at approximately 20) minutes, but it has been shown recently that a further late peak in motility may also occur in the second hour." In patients with IBS a different colonic response to food has been reported" "with a continuous increase in motility into the third postprandial

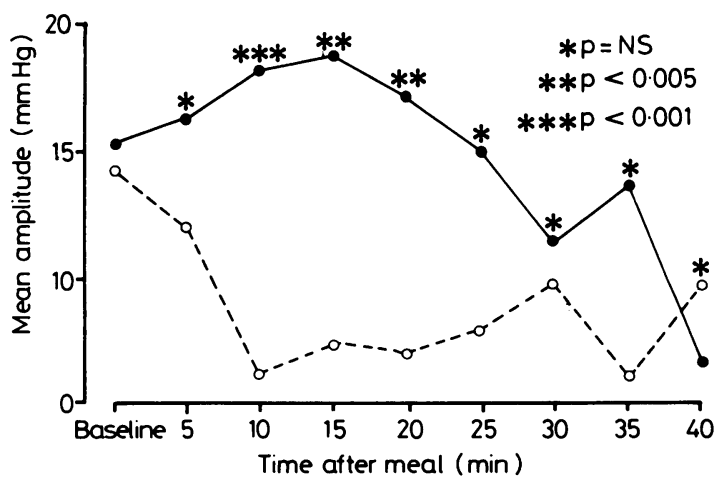

Fig. 3 Effect of nicardipine and saline on the amplitude of colonic contractions after meal. N Naline; $\mathrm{O}^{--}-\mathrm{O}$ nicardipine. 
hour without a transient return to baseline levels as seen in normal subjects. In the present study motility recording was limited to the early period after a meal because it was found that a number of subjects could not tolerate longer periods of continuous monitoring. When IBS patients were given $\mathrm{N}$ saline alone, however, a definite early peak of contractile activity occurred (Figs 1,2) followed by a return to basal levels. These results are therefore at variance to those previously noted." "It is now known that the constituents of a meal influence the colonic motor response ${ }^{12}$ and as the meal used in the present study differed from those of previous reports this may have affected the motility response. It has also been shown that a more exaggerated early response to food occurs in IBS patients whose symptoms are predominantly postprandial. Thus it is possible that patients with different symptom patterns may exhibit differing motility responses to food.

It is now known that contraction of gastrointestinal smooth muscle is dependent upon the flux of calcium ions across the cell membrane. ${ }^{*}$ It is becoming clear, however, that the effect of calcium antagonists on the contractile activity of the gut may vary according to site" so that although nifedipine has been shown to reduce the lower oesophageal sphincter pressure ${ }^{1:}$ this does not guarantee action on colonic smooth muscle. There have been two previous reports on the effect of calcium channel blocking agents on the gastrocolonic response in patients with IBS." "1t Both nifedipine ${ }^{1+}$ and octylonium bromide "were found to reduce the colonic response to food as measured by both myoelectrical activity and the motility index. In the present study the response to nicardipine was more impressive as gastrocolonic response was completely abolished. In the previous studies, however, the calcium antagonists were administered orally, whereas nicardipine given intravenously is likely to achieve higher circulating concentrations. It is therefore difficult to draw conclusions concerning the relative efficacies of these different preparations in inhibiting colonic smooth muscle contraction.

There is some evidence that the gastrocolonic response to a meal may be at least partially mediated by the stimulation of receptors situated in the duodenum. ${ }^{15}$ It is therefore possible that a drug which causes a decrease in the colonic response to food may be acting by delaying gastric emptying rather than by directly affecting colonic smooth muscle. There is as yet no information available concerning the effect of nicardipine on gastric motility. Previous studies of both nifedipine " and octylinium bromide," however, have revealed that these compounds do not signficantly effect gastric emptying. It seems likely therefore that the action of nicardipine is secondary to direct inhibition of colonic smooth muscle.
In conclusion therefore there is growing evidence that calcium channel blocking agents do reduce colonic activity in patients with IBS. Although of academic interest this action will only be of use clinically if accompanied by a significant decrease in symptomatology. The results of the present and previous studies provide a rational basis for clinical trials of these agents in IBS.

\section{References}

1 Chaudhary MB. Truelove SC. Human colonic motility: a comparative study of normal subjects, patients with ulcerative colitis and patients with irritable colon syndrome. I. Resting patterns of motility. II. The effect of prostigmine. Gastroenterology 1961: 40: 1-26.

2 Sullivan MA, Cohen S. Snape WJ. Colonic myoelectrical activity in irritable bowel syndrome. Effect of eating and anticholinergics. $N$ Engl J Med 1978; 298: 878-83.

3 Snape WJ, Battle WM, London RL, Cohen S. Increased colonic motility during exposure to a stressful situation. Dig Dis Sci 1985; 30: 4()-4.

4 Whitehead WE, Engel BT, Schuster MM. Irritable bowel syndrome. Physiological and psychological differences between diarrhoea predominant and constipation predominant patients. Dig Dis Sci 1980; 25: 404-13.

5 Connell AM, Jones FA, Rowlanes EN. Motility of the pelvic colon. Part IV Abdominal pain associated with colonic hypermotility after meals. Gut 1965; 6: 105-12.

6 Holdstock DJ, Misiewicz JJ, Waller SL. Observations on the mechanisms of abdominal pain. Gut 1969; 10: 19-31.

7 Prior A, Whorwell PJ. Management of irritable bowel syndrome. Biomed Pharmacother 1986; 40: 4-5.

8 Karaki H. Weiss GB. Calcium channels in smooth muscle. Gastroenterology 1984; 87: 96()-70.

9 Snape WJ, Matarazzo SA. Cohen S. Effect of eating and gastrointestinal hormones on human colonic myoelectrical and motor activity. Gastroenterology 1978; 75: $373-8$

10 Kerlin P, Zinsmeister A, Phillips S. Motor response to food of the ileum, proximal colon and distal colon of healthy human. Gastroenterology 1983; 84: 762-70.

11 Narducci F, Bassotti G, Granata MT. et al. Colonic motility and gastric emptying in patients with irritable bowel syndrome. Effect of pretreatment with octylonium bromide. Dig Dis Sci 1986; 31: 241-6.

12 Levinson S, Bhasker M. Gibson TR, Morin R, Snape WJ. Comparison of intraluminal and intravenous mediators of colonic response to eating. Dig Dis $\mathrm{Sci}$ 1985; 30: 33-9.

13 Gelford M, Rozen P. Gilat T. Isosorbide dinitrate and nifedipine treatment of achalasia; a clinical, manometric and radionuclide evaluation. Gastroenterology 1982; 83: 963-9.

14 Narducci F, Bassotti G, Gaburri M, Farroni F, Morelli A. Nifedipine reduces the colonic motor response to eating in patients with the irritable colon syndrome. $\mathrm{Am}$ J Gastroenterol 1985; 80: 317-9. 
15 Holdstock DJ, Misiewicz JJ. Factors controlling colonic motility: colonic pressures and transit after meals in patients with total gastrectomy, pernicious anaemia or duodenal ulcer. Gut 1970; 11: 100-10.
16 Traube M, Lange RC, McAllister RG, McCallum RW. Effect of nifedipine on gastric emptying in normal subjects. Dig Dis Sci 1985; 30: 710-2. 